\title{
POR UMA SOCIOLOGIA PÚBLICA DO ESPORTE NAS AMÉRICAS: UM CHAMADO EDITORIAL EM PROL DE UMA EDUCAÇÃO FÍSICA SOCIALMENTE RELEVANTE
}

\author{
FOR A PUBLIC SOCIOLOGY OF SPORT IN THE AMERICAS: AN EDITORIAL \\ CALL ON BEHALF OF A SOCIALLY ENGAGED SCHOLARSHIP ON \\ SPORT AND PHYSICAL EDUCATION
}

\author{
POR UNA SOCIOLOGÍA PÚBLICA DEL DEPORTE EN LAS AMÉRICAS: \\ UNA CONVOCATÓRIA EDITORIAL EN PRO DE UNA EDUCACIÓN FISICA \\ SOCIALMENTE RELEVANTE
}

\section{Peter Donnelly*, Alex Branco Fraga ${ }^{* \star}$, Angela Aisenstein ${ }^{\star * *}$}

Palavras-chave

Sociologia pública do esporte.

Educação Física.

Produtivismo

acadêmico.

Comunicação

científica.

Keywords

Public Sociology of

Sport.

Physical Education

Academic

productivism

Scientific

Communication.

Palabras clave

Sociología pública

del deporte.

Educación Física.

Productivismo

académico.

Comunicación

científica.
Resumo: Trata-se de um ensaio produzido de forma conjunta pelos três editores do número especial da revista Movimento - Por uma sociologia pública do esporte nas Américas: conquistas, desafios e agendas emergentes, proposto em comemoração ao vigésimo aniversário desta revista brasileira e inspirado nos dez anos do manifesto de Burawoy em favor de uma sociologia pública. $O$ texto está divido em três seções, a primeira, escrita originalmente em inglês, discute a importância de se praticar uma sociologia do esporte de caráter público e de se produzir pesquisas que efetivamente contribuam para o enfrentamento político de problemas concretos da sociedade. A segunda, escrita originalmente em português, trata dos efeitos do "produtivismo" acadêmico na política de comunicação científica brasileira, em especial para as ciências humanas e sociais, destacando a especificidade da Movimento na veiculação da produção sociocultural e pedagógica da educação física. A terceira, escrita originalmente em espanhol, cita os desafios enfrentados pela equipe editorial para a organização do número especial e apresenta de forma panorâmica o conteúdo dos textos que compuseram um chamado à produção científica socialmente relevante no campo.

Abstract: This essay was jointly written by the three editors of the special issue of Movimento For a Public Sociology of Sport in the Americas: Accomplishments, Challenges, and Emerging Agendas - celebrating the twentieth anniversary of this Brazilian journal and inspired by the tenth anniversary of Burawoy's manifesto for a public sociology. The article is divided into three sections. The first section, originally written in English, discusses the importance of practicing sociology of sport with a public character and producing research that effectively and concretely contributes to political engagement with society's problems. The second section, originally written in Portuguese, approaches the effects of academic "productivism" on Brazil's scientific communication policy, especially for the humanities and social sciences. It stresses the specific role played by Movimento in disseminating socio-cultural and pedagogical research in physical education. The third section, originally written in Spanish, lays out the challenges faced by the editorial team to organize the special issue and presents an overview of the content of the texts included in a call for a socially relevant scientific production in the field.

Resumen: Se trata de un ensayo producido de manera conjunta por los tres editores del número especial de la revista Movimento - Por una sociología pública del deporte en las Américas: conquistas, desafíos y agendas emergentes, propuesto en conmemoración al vigésimo aniversario de esta revista brasileña e inspirado en los diez años del manifiesto de Burawoy a favor de una sociología pública. El texto está dividido en tres secciones. La primera, escrita originalmente en inglés, discute la importancia de practicar una sociología del deporte de carácter público y de producir investigaciones que efectivamente contribuyan a enfrentar políticamente problemas concretos de la sociedad. La segunda, escrita originalmente en portugués, trata de los efectos del productivismo académico en la política de comunicación científica brasileña, en especial para las ciencias humanas y sociales, destacando la especificidad de la revista Movimento como vehículo de la producción sociocultural y pedagógica de la educación física. La tercera, escrita originalmente en castellano sintetiza los desafíos enfrentados por el equipo editorial para organizar el número especial y presenta de manera panorámica el contenido de los textos que compusieron un llamado a la producción científica socialmente relevante en el área.
*University of Toronto, Toronto, Canada.

E-mail: peter.donnelly@utoronto.ca

** Universidade Federal do Rio Grande do Sul, Porto Alegre, RS, Brasil.

E-mail: brancofraga@gmail.com

*** Universidad Nacional de Luján e Universidad de San Andrés, Provincia de Buenos Aires, Argentina. E-mail: aaisenstein@gmail.com

(c) (1) (8) Licence 


\section{A VISÃO DE ABYA YALA' A PARTIR DO NORTE: A (IR)RELEVÂNCIA DO TRABALHO SOCIOLÓGICO EM ESPORTE E CULTURA CORPORAL}

[O historiador socialista britânico E. P. Thompson] ajudou a manter a fronteira, imensamente produtiva em termos intelectuais e às vezes politicamente importante, entre 0 conhecimento acadêmico e 0 ativismo público. E ele sempre lamentou, acho eu, a forma como essa fronteira foi paulatinamente atenuada pela capacidade cada vez maior das universidades de absorver e domesticar o discurso intelectual (CALHOUN, 1994, p. 223).

Em um artigo publicado há pouco tempo na (revista estadunidense) Chronicle of Higher Education, o professor de Harvard Orlando Patterson (2014) se tornou o mais recente sociólogo a questionar "como os sociólogos transformaram a si próprios em irrelevantes". Ele aponta a ausência de sociólogos em painéis de especialistas que tratam de políticas nos Estados Unidos, a ponto de "os sociólogos passarem a ser espectadores distantes em vez de formuladores das políticas". Assim, Patterson se junta a um coro de vozes que pedem o resgate da sociologia pública, "usando nossos conhecimentos para ajudar a desenvolver políticas públicas e mitigar os problemas sociais em contextos em que a experiência e os dados possam, reciprocamente, informar o nosso trabalho".

A sociologia tem sido marginalizada das políticas públicas nos Estados Unidos, tanto por sua própria inércia quanto - talvez em um processo de marginalização mais deliberado - pelos órgãos de decisão política. No Canadá, contudo, a postura antissociológica do atual governo tem sido mais explícita. Repercutindo a afirmação de Margaret Thatcher, feita em 1987, de que "isso que se chama de sociedade não existe", o primeiro-ministro Stephen Harper respondeu, em 2013, a um chamado para buscar as causas fundamentais de um suposto plano terrorista no Canadá, afirmando que aquele não era momento para "praticar sociologia". Em 2014, argumentando contra uma investigação pública sobre 0 assassinato e 0 desaparecimento de um grande número de mulheres indígenas, o primeiro-ministro disse que tais casos deveriam ser tratados como uma série de crimes individuais e "não como um fenômeno sociológico". Essas declarações seguiram o cancelamento, pelo atual governo, em 2010, do formulário extenso que era obrigatório no censo realizado pela Statistics Canada (a agência canadense de estatísticas) - uma das melhores fontes de dados das ciências sociais no país.

A marginalização da sociologia ganha contornos ainda mais ideológicos quando vemos quem é convidado a participar e assessorar órgãos de formulação de políticas, e de quem são as palavras lidas e vozes ouvidas com mais frequência nos meios de comunicação quando se abordam os problemas sociais. Cientistas políticos e economistas, principalmente os que tendem a ver as pessoas como indivíduos e consumidores, e não como cidadãos e membros da sociedade, "têm dado suas opiniões em debates sobre [entre outras coisas] encarceramento, gangues e violência, índices de abandono no ensino médio, desemprego crônico e desconexão socioeconômica - todos os temas estudados em profundidade pelos sociólogos" (PATTERSON, 2014). Se a sociologia é considerada uma ameaça pela ordem capitalista neoliberal, nunca houve momento melhor para "praticar sociologia", como argumentaram muitos sociólogos canadenses em 2013.

1 Abya Yala, na linguagem do povo kuna, do Panamá, significa "terra em plena maturidade". O povo kuna ocupa a ponte entre as "Américas" do Norte e do Sul, e os povos indígenas das "Américas" e outros estão empregando cada vez mais a expressão para se referir a todo o continente. Seu uso é atribuído ao líder aimará ("boliviano") Takir Mamani: "Dar nomes estrangeiros a nossas cidades, aldeias e continentes equivale a submeter nossas vontades à identidade de nossos invasores e seus herdeiros" (ALBO, 1995, p. 33). 
A sociologia no Canadá e nos Estados Unidos tem vivido um conflito permanente em relação a seu propósito. ${ }^{2}$ Ela deve produzir "conhecimento pelo conhecimento" (ou seja, a disciplina acadêmica tradicional) ou "conhecimento pela humanidade" (uma abordagem mais engajada, relevante e prática)? Burawoy (2005) apresenta esse argumento, perguntando: "Sociologia para quem?" (O público somos nós mesmos ou outros?) e "Sociologia para quê?" (sociologia para finalidades estabelecidas ou para discutir finalidades e/ou valores).

Na classificação do trabalho sociológico feita por Burawoy (profissional, para políticas, crítico e público), é a esfera profissional que tem dominado o trabalho sociológico no Canadá e nos Estados Unidos durante a maior parte dos últimos 50 anos - um desequilíbrio que se reproduz nos processos de formação dos doutorandos e nas políticas de contratação de novos docentes/pesquisadores. Como salienta Patterson, "no esforço para nos mantermos academicamente puros, também nos tornamos, em grande parte, irrelevantes na construção dos mais importantes empreendimentos sociais de nossa época".

Contudo, a tipologia de Burawoy não visa classificar os sociólogos - muitos deles trabaIham em mais de um tipo de sociologia, alguns trabalham em todos os quatro tipos, e todos eles são importantes. Ingham e Donnelly (1990) afirmaram que todo o conhecimento sociológico é conhecimento prático; ${ }^{3}$ em outras palavras, o conhecimento sociológico pode "fazer diferença". No entanto, o trabalho sociológico encontra diferentes expressões em diferentes países. Talvez a hegemonia da sociologia profissional não exista na mesma medida nos países do centro e do sul de Abya Yala, e "talvez somente no contexto de uma forte sociologia profissional é que precisemos desenvolver a ideia de uma 'sociologia pública"' (BURAWOY, 2007, p. 7).

Embora nossa disciplina tenha surgido na "América" do Norte, a partir da sociologia e da educação física como sociologia profissional do esporte, ${ }^{4}$ as abordagens práticas de educação física e do esporte têm continuamente levado sociólogos do esporte a se preocupar com os problemas sociais. No entanto, embora a sociologia e a sociologia do esporte no Canadá e nos Estados Unidos tenham sido afetadas pelos movimentos antiguerra, anticoIoniais, antipobreza, bem como de direitos civis e de mulheres, de meados do século XX, e embora a sociologia do esporte tenha produzido rotineiramente pesquisas que, em maior ou menor grau, "fizeram diferença" (DONNELLY, 2015; DONNELLY; ATKINSON, 2015), parece que o chamado de Burawoy (2005) por uma sociologia pública "atingiu um nervo", e não apenas na "América" do Norte.

O Primeiro Fórum sobre Sociologia realizado pela Associação Internacional de Sociologia (AIS), em 2008, abriu com um seminário sobre como essa disciplina estava mudando. Entre os 19 trabalhos apresentados, uma gama bastante ampla de culturas linguísticas e nacionais estava representada (embora a Teoria do Sul - Connell, 2007 - estivesse bastante limitada e o inglês fosse a língua majoritária), e o autor mais citado tenha sido Burawoy (posteriormente publicado por Kalekin-Fishman e Denis, 2012). Como observa um comentador, "[a sociologia] chegou a muitos resultados quando manteve os pés no chão e se ateve a estudar o mundo real" (HUSBANDS, 2012). Ele prossegue observando que muitas das principais preocupações atuais, como mudança climática, migração em massa, desigualdades econômicas e assim por diante, são tratadas pelos autores "que reconhecem que a principal tarefa da sociologia - para

\footnotetext{
2 Partes do que segue são adaptadas de Donnelly (2015).

3 Com essa afirmação, eles estavam reconhecendo suas influências sociológicas, como Peter Berger e C. Wright Mills, que afirmavam que 0 conhecimento sociológico poderia mudar a sua vida e as vidas de outras pessoas.

4 Ver Donnelly (2015) para uma breve explicação sobre essas origens.
} 
ter qualquer futuro que valha a pena - é analisar e enfrentar essas questões com pesquisas significativas sobre como elas afetarão a humanidade e como alguns de seus piores efeitos podem ser atenuados" (HUSBANDS, 2012).

Nós gostaríamos de levar essa afirmação ainda mais adiante e dizer que o trabalho dos sociólogos do esporte, para que tenha futuro, deve ser prático, deve ser público e deve estar pronto para fazer diferença. Precisamos nos questionar se as nossas perguntas de pesquisa, bem como as dos nossos alunos, são relevantes em termos de problemas atuais e futuros. Será que o esporte, como está constituído hoje, é um esporte sustentável (no qual trataríamos de problemas relacionados à mudança climática, ao meio ambiente e ao tamanho e ao custo de esportes e eventos)? Do ponto de vista do esporte e da cultura corporal, também podemos continuar a abordar, entre outros temas, a pobreza e a desigualdade social, os conflitos e a resolução de conflitos, a participação, os determinantes sociais da saúde e da propagação de doenças não transmissíveis, os direitos humanos e os direitos trabalhistas dos atletas e daqueles envolvidos nas indústrias de apoio ao esporte e às práticas corporais, e à democratização da participação, dos participantes e da governança. Se não contribuirmos para a resolução dos principais problemas que o mundo enfrenta hoje, continuaremos contribuindo para a nossa marginalização na academia e nos fóruns onde se discutem as políticas públicas.

\section{AO SUL DE ABYA YALA: EFEITOS DO PRODUTIVISMO ACADÊMICO NA COMUNICA- ÇÃO CIENTÍFICA EM EDUCAÇÃO FÍSICA}

Acreditamos que entre os povos Ibero-Americanos a convivência deve ser pautada também pela fraternidade e pelo enfrentamento solidário dos problemas sociais que afligem a maioria dos viventes no continente (EDITORIAL, 2000, p. 4).

O editorial do último fascículo do ano de 2000 da revista Movimento anunciava o lançamento da seção "Mercosul"', cujos objetivos centrais eram abrir espaço para a publicação de textos em língua espanhola e se tornar um canal de divulgação do conhecimento produzido pela área nos países ibero-americanos. $O$ texto inaugural foi La configuración postmoderna del cuerpo humano, de autoria do educador espanhol Conrado Vilanou (Universidad de Barcelona) e o de encerramento foi Olympia: la mirada femenina sobre los juegos olímpicos de Berlín, da socióloga argentina María Graciela Rodríguez (Universidad de Buenos Aires), publicado no último fascículo de 2002. Apesar da pouca duração, a seção Mercosul sinalizava àquela época a intenção da comissão editorial de começar a trilhar um processo de internacionalização com os "pés" no território latino-americano e o "olhar" na divulgação de pesquisas engajadas e socialmente relevantes para o continente; propósitos reafirmados de modo mais incisivo neste número especial comemorativo aos 20 anos da Movimento.

O editorial do último fascículo de 2002 não mencionava que o ensaio de María Graciela Rodríguez seria a despedida da seção Mercosul, porém anunciava que naquele momento se encerrava uma etapa da política editorial da revista que levou a mudanças estruturais significativas dali em diante. A partir do primeiro número de 2003, a Movimento não mais publicaria textos da subárea biodinâmica e focaria na publicação de textos das subáreas sociocultural e

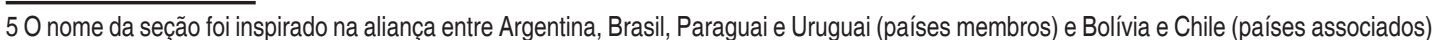
criada com o objetivo de estabelecer regras comerciais para livre circulação de bens e serviços entre os países Cone Sul do Continente Americano (BRASIL, 2014a). 
pedagógica ${ }^{6}$ (EDITORIAL, 2002). Conforme Stigger, Fraga e Molina Neto (2014), esta decisão foi tomada levando em consideração o histórico de publicações da própria revista e visando atender algumas das exigências de padronização editorial para indexação em bases de dados nacionais e internacionais. "Esse foi um momento importante e uma decisão que em muito repercutiu na 'vida' da revista Movimento dali em diante, pois aí foram lançados os alicerces sobre os quais o periódico se construiu e consolidou um lugar específico no campo acadêmico da Educação Física" (STIGGER; FRAGA; MOLINA NETO, 2014, p. 797).

Focar na especificidade das subáreas sociocultural e pedagógica da educação física em um cenário acadêmico onde predomina a produção da subárea biodinâmica, e se exige dos docentes da pós-graduação brasileira a publicação de artigos em escala industrial, foi um modo de se posicionar neste "campo de batalha de utopias reais" (BURAWOY, 2012) que tem privilegiado as pesquisas e os veículos científicos orientados pelas ciências naturais e marginalizado os orientados pelas ciências sociais e humanas.

No Brasil, a qualidade da produção de um pesquisador tem sido medida pela quantidade de artigos que ele consegue publicar em periódicos científicos bem ranqueados na sua área, independentemente do desenho teórico-metodológico adotado. O ranqueamento das revistas científicas se dá por um sistema de pontuação (QUALIS-Periódicos7) que as estratifica tomando como referência, preferencialmente, o fator de impacto atribuído pelo Journal of Citation Reports (JCR) a partir de citações coletadas na Web of Science (WoS) e o Scimago Journal Ranking (SJR), que coleta as citações no Scopus (PACKER, 2014). Quanto mais alto o impacto de uma revista, mais pontos o pesquisador obtém com um artigo nela publicado.

Para ser considerado "produtivo" um pesquisador deve ter, a cada quatro anos ${ }^{8}$, uma quantidade de artigos condizente com a mediana da sua área, que é calculada somente ao final do quadriênio com base na produção de todos os docentes credenciados em programas de pós-graduação. A qualidade de um programa de pós-graduação também é mensurada, preponderantemente, pela capacidade dos seus docentes de publicar artigos em grande escala dentro do mesmo período, ou seja, um programa de pós-graduação depende de docentes "produtivos"9 para obter uma boa nota. Este intricado aparato avaliativo é utilizado como parâmetro pelas universidades e agências de fomento para o financiamento de projetos de pesquisa, concessão de bolsas para estudantes nos diferentes níveis de ensino, classificação de professores em concursos públicos e para o credenciamento/descredenciamento de docentes dos programas de pós-graduação no Brasil (JOB, FRAGA, MOLINA NETO, 2008). Esta política de indução da produção centrada na publicação de artigos em revistas científicas se convencionou chamar de "produtivismo acadêmico".

\footnotetext{
6 Edson Manuel e Yara Carvalho (2011), ao buscarem caracterizar academicamente a educação física no Brasil por meio da análise das linhas de pesquisa dos programas de pós-graduação, identificaram três subáreas: biodinâmica, que compreende basicamente subdisciplinas como bioquímica do exercício, biomecânica, fisiologia do exercício, controle motor, aprendizagem e desenvolvimento motor; sociocultural, trata de temas da área pelo viés da sociologia, da antropologia, da história e da filosofia; e pedagógica, que investiga temáticas pertinentes à formação de professores, aos currículos escolares, aos métodos de ensino, a didática, à pedagogia do esporte, e as teorias da educação de um modo geral.

7 Sistema brasileiro de avaliação de periódicos criado e mantido pela Coordenadoria de Aperfeiçoamento de Pessoal de Nível Superior (CAPES) para classificar e listar os periódicos do mundo inteiro nos quais é divulgada a produção científica de docentes credenciados em programas de pós-graduação. Cada área de conhecimento possui o seu próprio Qualis com regras estipuladas por comissão de especialistas (BRASIL, 2014b).

8 Em 2014 a CAPES decidiu alterar o interstício para avaliação dos programas para quatro anos, que até então era de três anos.

9 Em artigo publicado em 2011, Maria Luisa Sandoval Schmidt analisa o episódio conhecido como a "lista dos improdutivos", matéria publicada em 22 de fevereiro de 1988, domingo, no jornal Folha de S.Paulo, na qual eram divulgados "nomes de professores e pesquisadores da Universidade de São Paulo (USP) que não teriam escrito ou publicado no período de 1985 a 1986” (2011, p. 315).
} 
Se por um lado esta política contribuiu para que o país alcançasse a $13^{\underline{a}}$ posição no ranking dos países produtores de ciência com base na aferição da WoS, e indiretamente a indexação de várias revistas em bases de dados internacionais (PACKER, 2014, BIANCHETTI; VALLE, 2014), por outro gerou problemas de toda a ordem na organização do sistema de pós-graduação (KUENZER; MORAES, 2005, MANOEL; CARVALHO, 2011, SILVA; SACARDO; SOUZA, 2014), no processo de trabalho dos pesquisadores (MANCEBO, 2013), na conduta ético-investigativa (CASTIEL; SANZ-VALERO, 2007), na formação de alunos na graduação (ALCADIPANI, 2011), no sistema de comunicação da ciência (DOMINGUES, 2014), na saúde dos pesquisadores (DE MEIS, 2003, BERNARDO, 2014) e na gestão dos periódicos das mais diversas áreas de conhecimento (REGO, 2014).

O produtivismo acadêmico tem afetado a política de divulgação científica brasileira e de modo especial o processo editorial das revistas dedicadas à veiculação da produção do conhecimento das ciências humanas e sociais. Desde a implantação do Sistema Eletrônico de Editoração de Revistas (SEER) ${ }^{10}$ em 2003, ferramenta criada pelo Instituto Brasileiro de Ciência e Tecnologia (IBICT) a partir da customização do Open Journal Systems (OJS), muitas revistas já consolidadas na área puderam ser editadas eletronicamente a um custo praticamente zero e dentro dos padrões editoriais internacionais válidos para periódicos online ${ }^{11}$. Neste formato, as revistas puderam automatizar a gestão editorial, aumentando a quantidade de artigos publicados, acelerando o processo avaliativo e ampliando o acesso ao conteúdo. $\mathrm{Na}$ medida em que o número de revistas aumentou, e a qualidade dos textos publicados diminuiu (REGO, 2014, PACKER, 2014), a pressão passou a ser pela indexação em bases de dados internacionais, em especial WoS e Scopus, induzindo as revistas das ciências humanas e sociais a seguirem critérios bibliométricos mais afeitos aos veículos de comunicação científica que operam em escala industrial para atender o mercado global da ciência. As revistas que conseguiram ingressar em bases de dados internacionais prestigiadas, ou até mesmo em bases nacionais emergentes no cenário mundial como o Scielo ${ }^{12}$; agregaram mais visibilidade e, por isso mesmo, passaram a lidar com um volume ainda maior de artigos submetidos, aumentando exponencialmente a carga de trabalho da equipe editorial e o número de artigos publicados sem tanta relevância social quanto se gostaria.

As poucas revistas voltadas para as ciências humanas e sociais que conseguiram "passar de fase" neste intricado jogo da internacionalização dos periódicos, depararam-se com uma frente de batalha ainda mais dura: aumentar o fator de impacto da produção veiculada tendo como referência, predominantemente, o JCR (WoS) e o SJR (Scopus). Conforme Packer (2014), além de os mecanismos das bases de dados internacionais favorecerem os veículos de divulgação dos países desenvolvidos, é limitada a cobertura de periódicos de ciências humanas e sociais nestas bases, em especial o WoS, o que leva a uma taxa de citação dos artigos bem mais baixa em relação ao conjunto das áreas. Portanto, problemas como a pouca participação de autores estrangeiros, a baixa colaboração internacional em pesquisas nacionais e a escrita em língua portuguesa, apontados como causas do baixo impacto dos artigos brasileiros em todas as áreas (PACKER, 2014), agrega-se o fato de que os

10 Mais informações estão disponíveis em <http://seer.ibict.br/index.php?option=com frontpage\&ltemid=1> Acesso em: 20 dez. 2014.

11 De acordo com Packer (2014, p. 313), "o Brasil ocupa o segundo lugar em número de periódicos em acesso aberto, logo depois dos Estados Unidos".

12 "O SciELO caracteriza-se por ser uma coleção multidisciplinar de revistas científicas nacionais de 16 países (da América Latina, Caribe, Europa e África do Sul), pioneira na adoção do acesso aberto. Criado em 1998, é um programa da Fundação de Amparo à Pesquisa do Estado de São Paulo (FAPESP), e conta com o apoio do Centro Latino-Americano e do Caribe de Informação e Ciências da Saúde (BIREME) e do

Conselho Nacional de Desenvolvimento Científico e Tecnológico (CNPq)" (REGO, 2014, p. 327). 
pesquisadores das ciências humanas e sociais geralmente priorizam o formato livro e seus temas de estudo tem o público nacional como alvo (REGO, 2014).

A busca pela citação na selva produtivista globalizada tem levado boa parte das revistas brasileiras a tomarem decisões extremas tais como, por exemplo, somente aceitarem a submissão de artigos em língua inglesa. Afora a desvalorização do produto nacional, este tipo de política editorial acaba gerando efeito contrário, pois artigos em português têm ajudado a manter as taxas de citação de revistas brasileiras em nível equivalente aos das revistas dos BRICS e um desempenho destacado no âmbito da América Latina (PACKER, 2014). Além destes equívocos, a pressão pela melhoria de desempenho nas citações acaba gerando desdobramentos ainda mais nefastos. Preocupada com a hipervalorização destes índices bibliométricos e com distorções na base produtiva do campo de conhecimento, o editorial do fascículo 3 de 2013 da revista Movimento apresentava posicionamento crítico ao crescimento artificial da citação na bases de dados WoS em 2012. Naquele ano, 64 periódicos que constavam no JCR de 2011 foram excluídos por utilizarem estratégias de manipulação das citações, dentre os quais quatro brasileiros, fato que trouxe grandes repercussões para o setor editorial nacional (EDITORIAL, 2013).

Em 2014, ao completar 20 anos de existência, a Movimento se propôs a enfrentar as adversidades impostas por esta nova fase do jogo editorial internacional convidando estudiosos do continente americano a compartilharem suas experiências e a reagirem em seus próprios idiomas a essa nova ordem mundial. Por ser vinculada a Escola de Educação Física da Universidade Federal do Rio Grande do Sul, financiada por agências de fomento públicas (CAPES, CNPq), editada em plataforma eletrônica de acesso livre (SEER) ${ }^{13}$, indexada na WoS e avaliada pela Social Science Index, a Movimento reafirma nesse número especial seu compromisso com o desenvolvimento acadêmico-científico do campo da Educação Física em interface com as ciências humanas e sociais, mantendo acesa a chama crítica que fez desta revista do extremo sul do Brasil um polo de resistência à mercadorização do conhecimento em educação física e esportes.

Para não perder o trem desta história, e muito menos se tornar "refém do produtivismo acadêmico"14, a Movimento segue ciente de que "o jogo é jogado dentro da regra do jogo"15. E para seguir em campo é preciso contar com pesquisadores de diferentes partes do mundo engajados na resolução dos problemas sociais que afligem de modo especial a população ao norte e ao sul de Abya Yala.

\section{PARA ALÉM DAS FRONTEIRAS DE ABYA YALA: ASSERTIVAS, DESAFIOS E REALIZA- ÇÕES DE UMA EDIÇÃO ESPECIAL}

A partir da afirmação de Michael Burawoy - sugerindo que a sociedade civil está atualmente sob ameaça dos interesses dominantes do mercado e do Estado - e reconhecendo que talvez não haja outro domínio da vida social em que isso seja tão visível quanto no esporte, o chamado para esta edição especial se propunha a acompanhar o argumento do sociólogo "por

\footnotetext{
13 A revista Movimento passou a ser editada pela plataforma SEER a partir de maio de 2007. Antes a revista circulava apenas em sua versão impressa, que era distribuída de forma gratuita, preferencialmente, para as bibliotecas de instituições públicas com vínculo com a área de formação em educação física. 
uma Sociologia Pública 'vigorosa', ancorada na visão de que as lutas da sociedade civil podem assumir formas distintas em resposta a diferentes condições opressivas encontradas em cada cenário social".

O texto do chamado dizia que "apesar dos numerosos esforços para consolidar o acesso ao esporte e à atividade física como um direito humano fundamental, políticas públicas e programas sociais de esporte e lazer tendem a figurar entre os primeiros a sofrer cortes em tempos de austeridade fiscal". Também se enfatizava que "em todo o continente americano - e mais expressivamente na América do Norte - a emergência de políticas neoliberais desencadeou uma mercantilização sem paralelo dos meios de acesso e dos espaços para a prática de esporte e da atividade física, ao mesmo tempo em que a capacidade do Estado de oferecer oportunidades de participação nessas atividades diminui significativamente", e estendia a preocupação à "ameaça da privatização [...] generalizada na maior parte das sociedades capitalistas".

O argumento pelo qual se convocava quem faz sociologia (profissional, crítica, orgânica, pública) a se envolver na escrita de manuscritos não perdia de vista que, nos últimos anos, em alguns países ao sul de Abya Yala - como Brasil, Equador, Argentina e Bolívia - as políticas de participação no esporte experimentaram uma alocação sem precedentes de recursos, mas também reconhecia que "não está ainda muito claro, contudo, se essas políticas foram capazes de efetivamente contestar os valores hegemônicos engendrados pela monocultura dos esportes profissionais - ou se, ao contrário, ajudaram a reproduzi-los."

Portanto, sob o título "Por uma sociologia pública do esporte nas Américas: conquistas, desafios e agendas emergentes", a edição especial de Movimento procurou "enfatizar como estudiosos do esporte situados em várias partes do mundo - e principalmente nas Américas - têm enfrentado alguns dos desafios apresentados acima, que compromissos têm assumido junto aos seus respectivos 'públicos' e audiências, e de que modo têm defendido os interesses da sociedade civil" e, nesse marco, apostou em atualizar o compromisso dos intelectuais do campo e incentivar o seu reposicionamento como intelectuais públicos.

A resposta ao chamado foi imediata. A equipe editorial teve a satisfação de receber muitos manuscritos e o desafio de selecionar - por meio de avaliação por pares em sistema duplo-cego - aqueles que, a seu ver, melhor respondessem ao escopo desta edição especial de caráter particular.

Os textos desta edição foram escritos por colegas de diferentes países: Argentina, Brasil, Canadá, Chile, Espanha, Estados Unidos, México, Reino Unido e Uruguai; ${ }^{16}$ Além disso, vários artigos são produto da "associação intelectual" entre colegas de diferentes países que trabalharam em conjunto (a partir de espaços compartilhados de formação acadêmica) para trazer ao debate público questões de seu cotidiano (social e profissional) que muitas vezes são internalizadas como práticas sociais naturais.

Os trabalhos podem ser organizados em dois grupos. O primeiro reúne os textos que atualizam, discutem e relacionam a assertiva de Burawoy às perspectivas teóricas dos autores e do campo acadêmico-científico em que operam (tanto no contexto latino-americano quanto no europeu). No segundo se encontram as produções que consideram a sociologia como ferramenta de análise e intervenção para entender e tratar de problemas ou temas específicos das realidades sociais que cercam o esporte e a cultura física em geral, em seus respectivos 
países, mas não se reduzem a eles. Todos permitem reconhecer os contextos locais e nacionais a partir dos quais emergem as preocupações intelectuais dos autores, assim como o cenário da produção das condições objetivas de onde derivam essas preocupações; que muitas vezes também são globais. Ao mesmo tempo, apostam em fazer interpretações e propostas de intervenção não convencionais, que possam ser entendidas como intercâmbios intelectuais supranacionais, sem pretensão de universalidade.

No entanto, se é verdade que uma política (neste caso, editorial) deve ser avaliada mais por seus efeitos do que por suas assertivas (e cada leitor fará sua avaliação), vale a pena Ihes propor uma leitura completa da edição especial. Para além do interesse específico que possa orientar a escolha de um ou outro artigo, e embora a edição especial não tenha tido uma coordenação centralizada para sua redação (razão pela qual os autores de cada artigo escrevem a partir de perspectivas distintas), os textos, como um todo, podem produzir um efeito de conjunto. A equipe editorial apostou em incentivar a criação de um espaço público onde se expressasse uma "comunidade sociológica". Este princípio foi seguido pelos colegas de diferentes países que, em sua função de pares avaliadores, leram as primeiras versões, questionaram os autores sobre suas afirmações e argumentos e os levaram a refinar e dar maior clareza a seus escritos. Se, em certa medida, o produto final atende aos propósitos que moveram a equipe editorial, só nos resta agradecer a todos os colegas pelo trabalho realizado, pelo esforço para responder às demandas e pela paciência para esperar que este fascículo viesse à tona.

\section{REFERÊNCIAS}

ALBO, X. Our identity starting from pluralism in this base. In: BEVERLEY, J.; OVIEDO, J.; ARONNA, M. (Org.). The postmodern debate in Latin America. Durham, NC: Duke University Press, 1995. p. 18-33.

ALCADIPANI, R. Resistir ao produtivismo: uma ode à perturbação Acadêmica. Cadernos EBAPE.BR, Rio de Janeiro, v. 9, n. 4, p. 1176-1178, 2011.

BERNARDO, M. H. Produtivismo e precariedade subjetiva na universidade pública: o desgaste mental dos docentes. Psicologia \& Sociedade, Belo Horizonte, v. 26, n. especial, p. 129-139, 2014.

BIANCHETTI, L.; MACHADO, A. M. N. Reféns da produtividade: sobre produção do conhecimento, saúde dos pesquisadores e intensificação do trabalho na pós-graduação. In: REUNIÃO ANUAL DA ANPED, 30, 2007, Rio de Janeiro. Anais... Rio de Janeiro: ANPEd, 2007.

BIANCHETTI, L.; VALLE, I. R. Produtivismo acadêmico e decorrências às condições de vida/trabalho de pesquisadores brasileiros e europeus. Ensaio: avaliação e políticas públicas em Educação, Rio de Janeiro, v. 22, n. 82, p. 89-110, 2014.

BRASIL. Congresso Nacional. Comissão Parlamentar Conjunta do Mercosul. Mercado Comum do Sul: Mercosul. Disponível em: <http://www.camara.gov.br/mercosul/blocos/MERCOSUL.htm>. Acesso em: 10 dez. 2014a.

BRASIL. Coordenadoria de Aperfeiçoamento de Pessoal de Nível Superior. Classificação da produção intelectual. 2014b. Disponível em: <http://www.capes.gov.br/avaliacao/instrumentos-deapoio/classificacao-da-producao-intelectual> Acesso em: 10 dez. 2014. 
BURAWOY, M. For public sociology. American Sociological Review, Thousand Oaks, v. 70, n. 1, p. 4-28, 2005.

BURAWOY, M. Public sociology: Mills vs. Gramsci. Sociologica, Bologna, n. 1, p. 7-13, 2007.

BURAWOY, Michael; VON HOLDT, Karl. Conversations with Bourdieu: the Johannesburg moment. Johannesburg: Wits University Press, 2012.

CALHOUN, C. E. P. Thompson and the discipline of historical context. Social Research, New York, v. 61, n. 2, p. 223-243, 1994.

CASTIEL, L. D.; SANZ-VALERO, J. Entre fetichismo e sobrevivência: 0 artigo científico é uma mercadoria acadêmica? Cadernos de Saúde Pública, Rio de Janeiro, v. 23, n. 12, p. 3041-3050, dez. 2007.

CORNNELL, R. Southern theory: The global dynamics of knowledge in social science. Cambridge: Polity, 2007.

DE MEIS, L. et al. The growing competition in Brazilian science: rites of passage, stress and burnout. Brazilian Journal of Medical and Biological Research, Ribeirão Preto, v. 36, n. 9, p. 1135-1141, 2003.

DOMINGUES, I O sistema de comunicação da ciência e o taylorismo acadêmico: questionamentos e alternativas. Estudos Avançados, v. 28, n. 82, p. 225-250, 2014.

DONNELLY, P. Assessing the sociology of sport: on public sociology of sport and research that makes a difference. International Review for the Sociology of Sport, London, 2015 (in press).

DONNELLY, P.; ATKINSON, M. Where history meets biography: toward a public sociology of sport. In: FIELD. R. (Org.). Contested Terrain: the continuing struggle for sport and recreation - essays in honour of Bruce Kidd. Toronto: University of Toronto Press, 2015. (no prelo)

EDITORIAL. Movimento, Porto Alegre, v. 19, n. 3, p. 10, jul./set. 2013.

EDITORIAL. Movimento, Porto Alegre, v. 7, n. 13, p. 4, 2000.

EDITORIAL. Movimento, Porto Alegre, v. 8, n. 3, p. 4, set/dez. 2002.

HUSBANDS, C. The Shape of Sociology for the $21^{\text {st }}$ Century: tradition and renewal, book review. 2012. Disponível em: <blogs.lse.ac.uk/lsereviewofbooks./2012/08/20/book-review-the-shape-of-

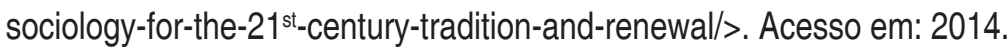

INGHAM, A.; DONNELLY, P. Whose knowledge counts?: the production of knowledge and issues of application in the sociology of sport. Sociology of Sport Journal, Champaign, v. 7, n. 1, p. 58-65, 1990.

JOB, I.; FRAGA, A. B.; MOLINA NETO, V. Invisibilidade das revistas brasileiras de educação física nas bases de dados. Cadernos de Biblioteconomia, Arquivística e Documentação, Lisboa, v. 1, p. 14-26, 2008.

KALEKIN-Fishman, D.; DENIS, A. (Org.). (2012). The shape of sociology for the $21^{\text {st }}$ century: tradition and renewal. London: Sage, 2012.

KUENZER, A. Z.; MORAES, M. C. M. de. Temas e tramas na Pós-Graduação em Educação.

Educação e Sociedade, Campinas, v. 26, n. 93, p. 1341-1362, set./dez. 2005.

LOVISOLO, H. Ponto de Vista: sobre a qualidade das publicações - questões e sugestões.

Movimento, Porto Alegre, v. 4, n. 7, p. 1563-1585, jul./dez. de 1997. 
MACHADO, A M. N.; BIANCHETTI, L. (Des)fetichização do produtivismo acadêmico: desafios para o trabalhador-pesquisador. Revista de Administração de Empresas, São Paulo, v. 51, n. 3, p. 244254, 2011.

MANCEBO, D. Trabalho docente e produção de conhecimento. Psicologia e Sociedade, Belo Horizonte, v. 25, n. 3, p. 519-526, 2013.

MANOEL, E. J.; CARVALHO, Y. M. C. Pós-Graduação na Educação Física brasileira: a atração (fatal) para a biodinâmica. Educação e Pesquisa, São Paulo, v. 37, n. 2, p. 389-406, maio/ago. 2011.

OLIVEIRA, M. B. On the Commodification of Science: the programmatic dimension. Science \& Education, Dordrecht, v. 22, p. 2463-2483, 2013.

PACKER, A. A eclosão dos periódicos do Brasil e cenários para o seu porvir. Educação e Pesquisa, São Paulo, v. 40, n. 2, p. 301-323, abr./jun. 2014.

PATTERSON, O. How sociologists made themselves irrelevant. Chronicle of Higher Education, $1^{\circ}$ dez. 2014. Disponível em: <http://chronicle.com/article/How-Sociologists-Made/150249/?cid=cr\&utm_ source=cr\&utm_medium=en>. Acesso em: 2014.

REGO, T. C. Produtivismo, pesquisa e comunicação científica: entre o veneno e o remédio. Educação e Pesquisa, São Paulo, v. 40, n. 2, p. 325-346, abr.jun. 2014.

SILVA, R. H. R.; SACARDO, M. S.; SOUZA, W. L. Dilemas da política científica da Educação Física brasileira em tempos de produtivismo acadêmico. Movimento, Porto Alegre, v. 20, n. 4, p. 1563-1585, out./dez. 2014.

STIGGER, M. P.; FRAGA, A. B.; MOLINA NETO, V. Os editoriais contam histórias: experiências do ofício de editor na Revista Movimento. Revista Brasileira de Ciências do Esporte, Florianópolis, v. 36, n. 4, p. 790-801. 2014.

SCHMIDT, M. L. S. Avaliação acadêmica, ideologia e poder Psicologia USP, São Paulo, v. 22, n. 2, p. 315-334, abr./jun. 2011.

VILACA, M. M.; PALMA, A. Diálogo sobre cientometria, mal-estar na academia e a polêmica do produtivismo. Revista Brasileira de Educação, Rio de Janeiro, v. 18, n. 53, p. 467-484, 2013. 
Autor correspondente:

Alex Branco Fraga

Rua Felizardo, 750, Jardim Botânico, Porto Alegre, Rio Grande do Sul, Brasil, CEP 90690-200

(J) Movimento, Porto Alegre, v. 20, n. esp., p. 9-20, 2014. 